\title{
Participação do ruminoretículo e omaso na superfície absortiva total do proventrículo de bovinos
}

João Luiz PRATTI DANIEL ${ }^{1}$ João Chrysostomo RESENDE JÚNIOR ${ }^{1}$

Fabiano Jardini CRUZ1

\section{Correspondência para:}

JOÃO LUIZ PRATTI DANIEL

Departamento de Medicina Veterinária

Universidade Federal de Lavras

Caixa Postal 3037

37200000 - Lavras - MG

joaocrj@ufla.br

Recebido para publicação: 17/01/2005 Aprovado para publicação: 13/07/2005

\author{
1 - Departamento de Medicina Veterinária da Universidade Federal de \\ Lavras, Lavras - MG
}

\section{Resumo}

Cerca de 50\% dos ácidos graxos voláteis (AGV) produzidos no ruminoretículo são absorvidos nesse compartimento e outros $50 \%$ passam com a fase fluida para o omaso e são absorvidos antes do duodeno. O objetivo deste trabalho foi mensurar a superfície de absorção do ruminoretículo e do omaso comparando-as com a magnitude de absorção. Oito bovinos adultos tiveram seu estômago removido imediatamente após o abate. Os compartimentos do estômago foram separados, pesados e tiveram fragmentos coletados em diversas regiões anatômicas. Procedeu-se a mensuração da área total da superfície interna por meio de captura e análise de imagens digitalizadas. A superfície absortiva do ruminoretículo $\left(7,7 \mathrm{~m}^{2}\right)$ foi maior $(P<0,001)$ do que a do omaso $\left(2,1 \mathrm{~m}^{2}\right)$. A relação superfície/ digesta, entretanto, foi maior $(P=0,07)$ no omaso $\left(0,22 \mathrm{~m}^{2} / \mathrm{Kg}\right)$ que no ruminoretículo $\left(0,12 \mathrm{~m}^{2} / \mathrm{Kg}\right)$, representando uma área superficial $83,3 \%$ maior no omaso por unidade de digesta. A área de um fragmento do saco ventral do rúmen apresentou correlação positiva $(0,84)$ com a área total da superfície do rúmen, indicando ser possível a estimativa da área total do órgão por meio de biópsia. A superfície absortiva dos compartimentos parece ser compatível com a magnitude de absorção, entretanto, estudos que comparem a taxa fracional de absorção de AGV entre os compartimentos devem ser realizados.

\section{Introdução}

A remoção (clearance) de ácidos graxos voláteis $(\mathrm{AGV})$, produtos finais da fermentação microbiana no ruminoretículo, ocorre por dois processos sendo que cerca de $50 \%$ são removidos por absorção pela parede do órgão e o restante passa para o omaso juntamente com a fase fluída ruminal e são absorvidos antes do duodeno ${ }^{1,2,3}$. Se a taxa de produção de $\mathrm{AGV}$ excede a taxa de clearance, haverá acúmulo desses dentro do ruminoretículo, podendo abaixar excessivamente o $\mathrm{pH}$ da digesta $\mathrm{e}$ desencadear acidose ruminal ${ }^{4}$, com efeitos negativos sobre a ingestão de alimentos ${ }^{5}$, a degradação ruminal da fibra ${ }^{6}$, a motilidade do rúmen ${ }^{7,8}$ e a morfologia da parede ruminal $^{9}$. A área da superfície interna do ruminoretículo está diretamente relacionada com a capacidade de absorção de $A G V^{10} \mathrm{e}$, como a magnitude de absorção entre o ruminoretículo e omaso é semelhante ${ }^{1,2}$, as superfícies absortivas devem ser compatíveis com suas funções.

A manipulação nutricional da morfologia e, conseqüentemente, da capacidade de absorção da parede do ruminoretículo é possível e tem sido preconizada para o controle da acidose ruminal em vacas leiteiras ${ }^{10}$. Há indícios de que também seja possível interferir nutricionalmente na morfologia do omaso ${ }^{11}$. A atuação sobre a morfologia omasal, uma linha de pesquisa incipiente, pode ser tão efetiva no controle de distúrbios digestivos decorrentes da produção e acúmulo excessivo de $A G V$ no rúmen ${ }^{12}$ quanto a 
manipulação da capacidade de absorção da parede ruminal.

O objetivo desse trabalho foi mensurar a extensão da superfície absortiva dos compartimentos do estômago comparando-a à magnitude de absorção de cada um.

\section{Materiais e Métodos}

Oito bovinos adultos, mestiços, não submetidos a jejum, com peso corporal de $479 \pm 185 \mathrm{Kg}$, alimentados a pasto, tiveram seu estômago removido imediatamente após o abate no matadouro, em um delineamento inteiramente casualizado. Os compartimentos do estômago (ruminoretículo, omaso e abomaso) foram separados e pesados, reportando-se o peso de cada compartimento e respectivas digestas. Após as pesagens dos compartimentos, já evacuados, foram retiradas amostras (fragmentos de $2,14 \mathrm{~cm}^{2}$ ), de diversas regiões anatômicas. Do saco dorsal foram retirados dois fragmentos, sendo um da parede direita e outro da esquerda, ambos na região intermediária entre os pilares cranial e caudal do rúmen, cinco centímetros dorsalmente ao respectivo pilar longitudinal. Do saco cego caudodorsal foi retirada uma amostra, cinco centímetros dorsalmente ao pilar caudal. No saco cranial, uma amostra foi retirada cinco centímetros cranialmente ao pilar cranial. Do saco cego caudo-ventral, foram retiradas duas amostras, uma cinco centímetros caudalmente ao pilar coronário ventral direito e outra cinco centímetros caudalmente ao pilar coronário ventral esquerdo. Do saco ventral foram retiradas três amostras, duas cinco centímetros ventralmente aos pilares longitudinais direito e esquerdo, e uma na extremidade ventrocranial do saco ventral (recesso do rúmen). No caso do retículo foi retirado um fragmento de $25 \mathrm{~cm}^{2}$ lateralmente ao sulco do retículo.

Os fragmentos foram imersos em solução tampão fosfato $(\mathrm{PBS}=0,79 \mathrm{~g}$ de $\mathrm{NaCl} ; 0,223 \mathrm{~g}$ de $\mathrm{Na}_{2} \mathrm{HPO}_{4} ; 0,0524 \mathrm{~g}$ de
$\mathrm{NaH}_{2} \mathrm{PO}_{4} ; \mathrm{H}_{2} \mathrm{O}$ q.s.p. $100 \mathrm{ml}$ ) e resfriados para preservar ao máximo as características biológicas. Após estes procedimentos órgãos e fragmentos em PBS foram acondicionados em caixas isotérmicas com gelo e transportados ao laboratório. Neste local retirou-se o tecido conjuntivo excedente da superfície serosal dos órgãos e efetuou-se dissecação dos compartimentos para posterior pesagem e mensuração da área superficial luminal das regiões de cada um.

As regiões anatômicas do ruminoretículo foram separadas isolando-se retículo, saco cranial, saco dorsal, saco cego caudodorsal, saco ventral e saco cego caudoventral. O peso de cada segmento anatômico foi registrado e as regiões foram fragmentadas de maneira a possibilitar digitalização de suas imagens através de um scanner (Scan Jet 4C, Hewlett Packard ${ }^{\circledR}$ ). Mensurações morfológicas dos fragmentos, previamente preservados em PBS, foram realizadas efetuando-se contagem do número de papilas ruminais presentes em cada fragmento. Posteriormente, a camada mucosa foi separada da muscular e serosa anotando-se seus pesos. Papilas ruminais foram seccionadas na base por meio de uma lâmina de bisturi e suas imagens digitalizadas através de scanner conforme Resende Júnior ${ }^{13}$, sendo suas áreas estimadas através do programa de análise de imagens UTHSCSA Image Tool (software livre), segundo Resende Júnior ${ }^{13}$.

A área epitelial total do rúmen foi calculada pela seguinte fórmula:

Área epitelial total $=($ área de epitélio contínuo - área da base das papilas) + (Número de papilas * área epitelial média das papilas). Assumiu-se a área da base de cada papila como um valor médio, 0,002 $\mathrm{cm}^{2}(0,02 \mathrm{~cm} \times 0,1 \mathrm{~cm})$, estimado por meio de um paquímetro.

O retículo foi fragmentado de maneira que possibilitasse a digitalização de sua imagem pelo scanner. O fragmento coletado forneceu parâmetros para estimativa da área total do retículo, considerando a morfologia peculiar desse órgão com a 
presença de cristas e células-do-retículo. Para estimativa da área das cristas foi utilizado um modelo matemático considerando a altura média das mesmas e o número de células-do-retículo do fragmento. A altura foi determinada com auxílio de um paquímetro contando-se o número de células-do-retículo presentes no fragmento. Pelo número de células-do-retículo estimouse o número de cristas, utilizando-se o seguinte modelo de regressão: $\mathrm{Y}=3,22+$ 2,24 x, onde $\mathrm{Y}$ é o número de cristas e x é o número de células-do-retículo. O comprimento das cristas foi obtido dividindo-se a aresta do fragmento $(5 \mathrm{~cm})$ pela raiz quadrada do número de células do fragmento. A área total das cristas do fragmento foi estimada pela seguinte fórmula:

Área das cristas do fragmento = número de cristas * altura média das cristas * comprimento médio das cristas.

A área total do fragmento foi calculada pela seguinte fórmula:

Área epitelial total do fragmento $=$ (área de epitélio contínuo + área das cristas do retículo)-(área da base das cristas do retículo).

Para a confecção do modelo assumiuse que as células do retículo são quadrangulares e a espessura da base das cristas como tendo um valor médio $(0,1 \mathrm{~cm})$, estimado pelo paquímetro.

Posteriormente, o fragmento do retículo teve a região mucosa separada da muscular e serosa, sendo registrados seus pesos.

Obtida a área e o peso do fragmento, a área total do retículo foi calculada pela proporção direta entre peso do fragmento e peso total do órgão. Outra estimativa empregou proporção direta entre área do fragmento e área do epitélio contínuo estimada pela análise de imagem. Ambas estimativas foram comparadas para verificação de sua acurácia. As papilas do retículo foram desconsideradas do cálculo da área devido ao seu tamanho diminuto.

O omaso, previamente seccionado, teve suas lâminas extraídas para posterior digitalização de suas imagens pelo scanner. Assumiu-se a espessura da base das lâminas como tendo um valor médio $(0,15 \mathrm{~cm})$, estimado pelo paquímetro. A área epitelial total foi calculada pela seguinte fórmula:

Área epitelial total do omaso $=$ (área do epitélio contínuo + área das lâminas do omaso) - (área da base das lâminas do omaso).

As papilas do omaso foram desconsideradas do cálculo da área devido ao seu tamanho diminuto.

A área de superfície absortiva, o peso dos compartimentos, o peso da mucosa e porção não mucosa, o peso da digesta dos compartimentos do proventrículo, o peso e $\mathrm{a}$ área superficial das regiões do rúmen foram analisados pelo procedimento GLM do pacote estatístico SAS de acordo com o seguinte modelo:

$\mathrm{Y}_{\mathrm{i}}=\mu+\mathrm{C}_{\mathrm{i}}+\mathrm{e}_{\mathrm{i}}$, onde, $\mu=$ média geral, $C_{i}=$ compartimento ou região do proventrículo, $\mathrm{e}_{\mathrm{i}}=$ erro independente $\mathrm{e}$ identicamente distribuído em suposta distribuição normal com média ì e variância $\mathrm{o}^{2}$. As médias foram comparadas uma a uma pelo teste Tukey.

Foram também estabelecidas correlações entre o peso e a área epitelial dos compartimentos, área de um fragmento do recesso do rúmen e a área total do compartimento.

\section{Resultados e Discussão}

O peso da digesta do ruminoretículo $(61,2 \mathrm{Kg})$ representou cerca de 13\% do peso corporal dos animais $(P=0,43)$. Do peso da digesta total do proventrículo, $15 \%$ encontrava-se no omaso $(10,0 \mathrm{~kg})$, valor menor $(P<0,001)$ que o encontrado no ruminoretículo $(71,2 \mathrm{~kg})$, o qual representou $85 \%$. O omaso tem sido considerado um sítio insignificante de fermentação microbiana ${ }^{14}$, entretanto, a quantidade de digesta sugere que sua importância fermentativa pode ser maior.

O peso do rúmen vazio proporcionalmente ao peso total do proventrículo 
foi $56 \%$, seguido pelo omaso $(23 \%)$, abomaso (11\%) e retículo (9\%). Apesar de ser citado na literatura ${ }^{14}$ que a capacidade de armazenamento do omaso é menor do que do abomaso, a grande densidade tecidual indica maior peso específico deste compartimento vazio.

A superfície absortiva (Tabela 1) do ruminoretículo $\left(7,7 \mathrm{~m}^{2}\right)$ foi maior $(P<0,001)$ do que a do omaso $\left(2,1 \mathrm{~m}^{2}\right)$. No entanto, a relação superfície/digesta, tendeu a ser maior $(P=0,07)$, no omaso $\left(0,22 \mathrm{~m}^{2} / \mathrm{Kg}\right)$ que no ruminoretículo $\left(0,12 \mathrm{~m}^{2} / \mathrm{Kg}\right)$, representando uma área superficial 83,3\% superior no omaso por unidade de digesta. Isso poderia compensar a menor superfície absortiva, mantendo o omaso como órgão de extrema importância no clearance de AGV. Caso a taxa fracional de absorção no omaso não seja eficiente, os $A G V$ excedentes passarão para o abomaso, podendo causar hipomotilidade desse órgão ${ }^{15,16} \mathrm{e}$, conseqüentemente, predispondo ao deslocamento de abomaso ${ }^{17}$. A manipulação da capacidade absortiva do omaso pode ser eficiente no controle de distúrbios digestivos importantes, especialmente em vacas leiteiras de alta produção. Outro fato a ser considerado é que nem toda superfície absortiva do ruminoretículo está em contato com a digesta constantemente, como ocorre no omaso. A maior parte do saco dorsal do rúmen está preenchida por gás entrando em contato com os AGV incorporados ao fluido ruminal, apenas por ocasião dos movimentos ruminais. Isso acentua a diferença existente entre a relação superfície/ digesta do ruminoretículo e omaso. A ausência de papilas bem desenvolvidas em algumas regiões do saco ventral e dos sacos cegos dorsal e ventral, observadas nesse trabalho, demonstram que alguns pontos dessas regiões anatômicas, mesmo localizadas mais ventralmente no rúmen, também não permanecem constantemente em contato com o fluido ruminal, provavelmente devido ao posicionamento dentro da cavidade abdominal permitir acúmulo de gás. O fato de que os AGV, presentes no fluido, atuam $\operatorname{direta}^{18} \mathrm{e}$ indiretamente $^{19}$ na variação do tamanho papilar confirmam esta hipótese. Nickel, Schummer e Seiferle ${ }^{11}$ descrevendo um corte transversal da cavidade abdominal de um bovino, na altura da quarta vértebra lombar, demonstram que a superfície visceral do saco ventral se projeta em direção dorsal, sob as vísceras, no antímero direito da cavidade abdominal. Isso possibilitaria o acúmulo temporário de gases nas regiões mais dorsais destas projeções.

Dentro das diversas regiões do rúmen (Tabela 1) os sacos ventral e cranial apresentaram as maiores superfícies absortiva, refletindo a maior área por unidade de peso de mucosa (Tabela 2) encontrada nessas regiões. Esse resultado deve-se certamente ao maior desenvolvimento epitelial estimulado por ação dos AGV presentes no fluido ruminal em contato permanente com regiões mais ventrais do rúmen. Os sacos cegos dorsal e ventral apresentaram área por unidade de mucosa semelhante aos supracitados (Tabela 2), no entanto, o tamanho menor dessas regiões anatômicas indicou menores superfícies absortivas quando comparadas aos sacos ventral e cranial (Tabela 1). O saco dorsal e o retículo foram menores tanto em área absortiva total (Tabela 1) quanto na relação área por unidade de mucosa (Tabela 2), resultado esperado devido à menor presença de papilas no saco dorsal e à função menos relacionada à absorção atribuída ao retículo ${ }^{20}$. A área superficial dos pilares representou menos de $1 \%$ do total do proventrículo, coerente com o fato dessas estruturas representarem concentrações da camada muscular, com função importante na compartimentalização e contração do rúmen ${ }^{20}$.

A correlação entre a superfície absortiva e o peso da camada mucosa das regiões do ruminoretículo foi positiva e alta $(0,80)$, mostrando que o peso da camada mucosa pode ser um bom indicativo da superfície absortiva.

A área de um fragmento do recesso 
Tabela 1 - Área média de superfície absortiva das diferentes regiões do rúmen, do retículo e do omaso e porcentagens que cada região representa na área total do proventrículo, de bovinos mestiços com média de $479 \mathrm{~kg}$ de peso corporal, alimentados a pasto

\begin{tabular}{ccc}
\hline Regiões & Área $\left(\mathrm{m}^{2}\right)$ & $\%$ da área total do proventrículo \\
\hline Saco ventral & $3,19^{\mathrm{a}}$ & $32,45 \%$ \\
Saco cranial & $2,38^{\mathrm{a}}$ & $24,21 \%$ \\
Saco cego caudoventral & $0,69^{\mathrm{b}}$ & $7,02 \%$ \\
Saco cego caudodorsal & $0,69^{\mathrm{b}}$ & $7,02 \%$ \\
Saco dorsal & $0,38^{\mathrm{b}}$ & $3,87 \%$ \\
Pilares & $0,08^{\mathrm{b}}$ & $0,81 \%$ \\
Retículo & $0,31^{\mathrm{b}}$ & $3,15 \%$ \\
Omaso & $2,11^{\mathrm{a}}$ & $21,46 \%$ \\
\hline
\end{tabular}

${ }^{\mathrm{a}, \mathrm{b}}$ Médias seguidas de letras diferentes na coluna não são iguais (Tukey $P<0,05$ )

Tabela 2 - Pesos médios da camada mucosa e relações área superficial/peso de mucosa das diferentes regiões do ruminoretículo, de bovinos com $479 \mathrm{Kg}$ em média de peso corporal, alimentados a past

\begin{tabular}{ccc}
\hline Regiāo & Peso $(\mathrm{Kg})$ & Área/Peso $\left(\mathrm{m}^{2} / \mathrm{Kg}\right)$ \\
\hline Saco ventral & $0,99 \mathrm{a}$ & $2,86 \mathrm{a}$ \\
Saco cranial & $0,67 \mathrm{ab}$ & $3,03 \mathrm{a}$ \\
Saco dorsal & $0,60 \mathrm{bc}$ & $0,59 \mathrm{~b}$ \\
Retículo & $0,54 \mathrm{bc}$ & $0,56 \mathrm{~b}$ \\
Saco cego caudo ventral & $0,34 \mathrm{c}$ & $1,79 \mathrm{a}$ \\
Saco cego caudo dorsal & $0,29 \mathrm{c}$ & $1,89 \mathrm{a}$ \\
\hline
\end{tabular}

a,b,c Médias seguidas de letras diferentes na coluna não são iguais (Tukey $P<0,05$ )

do rúmen apresentou correlação positiva com a área total da superfície do rúmen $(0,84)$ e com a superfície do ruminoretículo $(0,82)$, indicando ser possível a estimativa dessas áreas por meio de biópsia (Tabela 3). A correlação entre a área desse fragmento e a área total do proventrículo, também foi positiva $(0,58)$, possivelmente porque $\mathrm{o}$ epitélio do omaso e, conseqüentemente, sua área possam se proliferar estimulados por AGV como ocorre no epitélio ruminal. Costa ${ }^{11}$ detectou aumento de peso do omaso em bezerros mantidos em dieta líquida que receberam $A G V$ infundidos no rúmen, comparados aos animais do grupo controle, sugerindo estímulo dos AGV para o desenvolvimento do omaso.

\section{Conclusões}

Apesar da superfície absortiva do ruminoretículo ser maior do que a do omaso, a maior relação superfície digesta no omaso pode indicar que as superfícies absortivas são compatíveis com a magnitude de absorção de AGV. Estudos que comparem a taxa fracional de absorção de AGV entre os compartimentos, entretanto, devem ser realizados.

É possível a estimativa da área total do rúmen por meio de biópsia de um fragmento do saco ventral. 
Tabela 3 - Equações, graus de significância $(P)$ e $\mathrm{r}^{2}$ das equações confeccionadas para estimativa das áreas do rúmen $\left(\mathrm{cm}^{2}\right)$ e ruminoretículo $\left(\mathrm{cm}^{2}\right)$, por meio da mensuração da área de mucosa $\left(\mathrm{cm}^{2}\right) / \mathrm{cm}^{2}$ de epitélio contínuo ou através do peso de mucosa $(\mathrm{g}) / \mathrm{cm}^{2}$ de epitélio contínuo de fragmentos obtidos por biópsia do recesso do rúmen

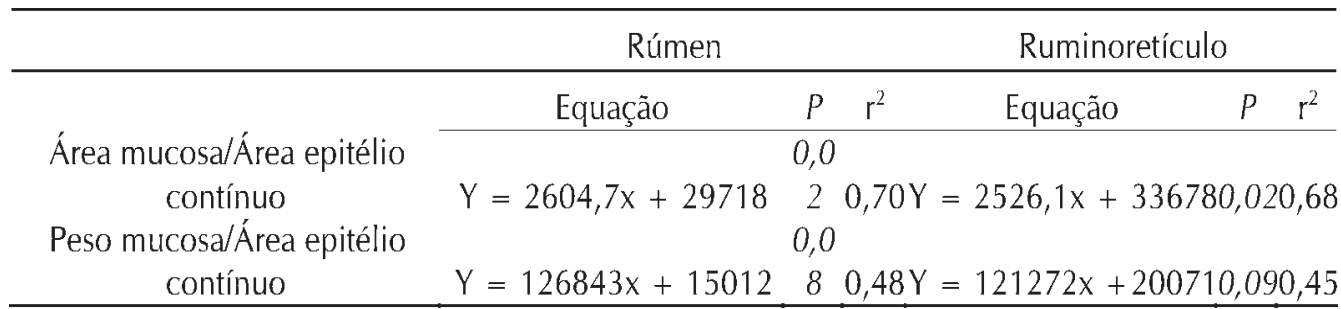

Participation of the reticulorumen and omasum in the total absorptive surface of the bovine forestomach

\section{Abstract}

About $50 \%$ of volatile fatty acids (VFA) produced in the reticulorumen are absorbed in this compartment. The other $50 \%$ pass with the fluid phase to the omasum and are absorbed before the duodenum. The objective of this experiment was to measure the absorption surface of the reticulorumen and omasum aiming to compare it with the absorption magnitude. Eight adult bovines had their stomachs removed immediately after slaughtering. The stomach compartments were separated and weighed. Fragments were collected from several anatomical regions. Measurements of the total area of the internal surface were taken through image capture and analysis. The reticulorumen absorptive surface $\left(7.7 \mathrm{~m}^{2}\right)$ was larger $(P<0.001)$ than the omasum absorptive surface $\left(2.1 \mathrm{~m}^{2}\right)$. The surface/digest ratio, however, was larger $(P=0.07)$ in the omasum $\left(0.22 \mathrm{~m}^{2} / \mathrm{kg}\right)$ than in the reticulorumen $\left(0.12 \mathrm{~m}^{2} / \mathrm{kg}\right)$, representing an omasum surface area for each digest unit $83.3 \%$ larger. The area of one of the rumen ventral sac fragments showed a positive correlation $(0.84)$ with the total rumen surface area, indicating that it is possible to estimate the total rumen area by biopsy. The absorptive surface of the forestomach compartments seem to be compatible with absorption magnitude. However, further studies comparing VFA fractional absorption rate among forestomach compartments should be carried out.
Key-words: Reticulorumen. Omasum. Volatile Fatty Acid. Bovine

\section{Referências}

1 PETERS, J. P.; SHEN, R. Y. W.; ROBINSON, J. A.; CHESSER, S. T. Disappearance and passage of propionic acid from the rumen of the beef steer. Journal of Animal Science, Champaign, v.68, n.10, p.3337-3349, 1990.

2 RESENDE JÚNIOR, J. C. Comparação entre técnicas para determinação do clearance ruminal de ácidos graxos voláteis. 2003. 133 p. Tese (Doutorado em Zootecnia) - Universidade Federal de Lavras, Lavras.

3 RUPP, G. P.; KREIKEMEIER, K. K.; PERINO, L. J.; ROSS, G. S. Measurement of volatile fatty acid disappearance and fluid flux across the abomasum of cattle, using an improved omasal cannulation technique.
American Journal of Veterinary Research, Schaumburg v. 55, n. 4, p. 522-529, 1994.

4 BARKER, I. K. , VAN DREUMEL, A. A.; PALMER. The alimentary system. In: JUBB, K. V. F., KENNEDY P. C. Pathology of domestic animals. 4th. ed. San Diego: Academic, 1995. v. 2.

5 ELLIOT, J. P.; DRACKLEY, J. K.; FAHEY, G. C.; SHANKS, R. D. Utilization of supplemental fat by dairy cows fed diets varying in content of nonstructural carbohydrates. Journal of Dairy Science, Champaign, v. 78, p. 1512-1525, July 1995.

6 GRANT, R. J.; MERTENS, D. R. Influence of buffer $\mathrm{pH}$ and raw cornstarch addition on in vitro fiber digestion kinetics. Journal of Dairy Science, Champaign, v. 75, p. 2762-2768, Oct. 1992. 
7 CRICHLOW, E. C.; CHAPLIN, R. K. Ruminal lact acidosis: relationship of forestomach motility to nondissociated volatile fatty acids levels. American Journal of Veterinary Research, Schaumburg, v. 46, p. 1908-1911, Sept. 1985.

8 LEEK, B. F.; HARDING, R. H. Sensory nervous receptors in the ruminant stomach and the reflex control of reticuloruminal motility. In: INTERNATINAL SYMPOSIUM OF RUMINANT PHYSIOLOGY, DIGESTION AND METABOLISM IN THE RUMINANT, 4., Sydney, 1975. Proceedings... Australia, 1975. p. 60.

9 GABEL, G.; ASCHENBACH, J. R.; MULLER, F. Transfer of energy substrates across the ruminal epithelium: implications and limitations. Animal Health Research Reviews, Wallingford, v. 3, n. 1, p. 15-30, June 2002

10 DIRKSEN, G.; LIEBICH, H. G.; BROSI, G.; HAGEMEISTER, H.; MAYER, E. Morphologie der pansenschleimhaut und fettsäureresorption beim rind bedeutende faktoren für gesunkheit und leistung. Zentralblatt für Veterinar Medizin, Berlin, v. 31, p. 414-430, July 1984.

11 COSTA, S. F. Alterações morfológicas induzidas por lactato, propionato e butirato sobre a mucosa ruminal e epiderme de bezerros. 2003. 90 p. Tese (Doutorado em Zootecnia) - Universidade Federal de Lavras, Lavras, 2003.

12 BUENO, L.; GOODALL, E. D.; KAY, R. N. B.; RUCKEBUSCH, Y. On the function of the sheep's omasum. Journal of Physiology, London, v. 227, n. 2, p. 14,1972

13 RESENDE JÚNIOR, J. C. Efeito da freqüência de alimentação concentrada sobre a morfologia das papilas do rúmen. 1999. $67 \mathrm{p}$. Dissertação (Mestrado em Zootecnia) - Universidade Federal de Lavras, Lavras, 1999.

14 NICKEL, R.; SCHUMMER, A.; SEIFERLE, E. The anatomy of the domestic animals: the circulatory system, the skin, and the cutaneous organs of the domestica mamals. Berlim-Hamburg: Verlag Paul Parey, 1981. v. 3, 610 p.

15 SVENDSEN, P. Etiology and pathogenesis of abomasal displacement in cattle. Nordisk Veterinary Medicine, Copenhagen, v. 21, p. 1, 1969.

16 BOLTON, J. R.; MERRIT, A. M.; CARLSON, G. M.; DONAWICK, W. J. Normal abomasal electromyography and emptying in sheep and the effects of intraabomasal volatile fatty acid infusion. American Veterinary Reserch, Shaumburg, v. 37, n. 12, p. 1387, 1976.

17 SHAVER, R. D. Nutritional risk factors in the etiology of left displaced abomasum in dairy cows: a review. Journal of Dairy Science. v. 80, n. 10, p. 2449-2453, Oct 1997.
18 SAKATA, T.; TAMATE, $\mathrm{H}$. Rumen epithelium cell proliferation accelerated by rapid increase in intraruminal butyrate. Journal of Dairy Science, Champaign, v. 61, p. 1109-1113, Aug. 1978.

19 SAKATA, T.; HIKOSAKA, K.; SHIOMURA, Y.; TAMATE, H. Stimulatory effect of insulin on ruminal epithelium cell mitosis in adult sheep. British Journal of Nutrition, Wallingford, v. 44, p. 325, 1980.

20 VAN SOEST, P. J. Nutritional ecology of the ruminant. $2^{\text {nd }}$ ed. Ithaca: Cornell University, 1994. 